\title{
Identifikasi Scouring sebagai Potensi Kelongsoran Tanggul Sungai Bengawan Solo berdasarkan Survei GPR (Studi Kasus Desa Widang, Kabupaten Tuban)
}

\author{
Dwa Desa Warnana* \\ Laboratorium Geofisika, Jurusan Fisika-FMIPA, \\ Institut Teknologi Sepuluh Nopember \\ Kampus ITS Sukolilo, Surabaya 61111
}

\begin{abstract}
Intisari
Telah dilakukan pengukuran dengan metode GPR (Ground Penetrating Radar) untuk mengidentifikasi scouring Sungai Bengawan Solo di Desa Widang, Kabupaten Tuban. Metode GPR merupakan salah satu metode geofisika yang memanfaatkan prinsip penjalaran gelombang elektromagnet dalam medium (tanah) yang kedalaman penetrasinya dan besar amplitudo yang terekam bergantung pada sifat dielektrik dari batuan atau media bawah permukaan dan frekuensi yang digunakan. Pada penelitian kali ini digunakan antena berfrekuensi 50 $\mathrm{MHz}$, yang bisa mencapai penetrasi hingga 25 - 30 meter. Pada hasil pengolahan data dan interpretasi menunjukkan bahwa terdapat pendangkalan sungai di daerah hulu. Sedangkan pada daerah menuju ke hilir dasar sungai mengalami penggerusan lapisan tanah (erosi) sehingga mengakibatkan dasar sungai menjadi curam. Penggerusan lapisan tanah (scouring) di sekitar tanggul diakibatkan oleh tanah yang mengandung lempung berpasir, pada pori batuannya tersisipi oleh air sungai. Potensi kelongsoran yang tinggi dapat dipicu dengan adanya scouring dan erosi aktif (terus menerus). Keadaan seperti ini ditemukan pada daerah pengukuran lintasan widang 2 dan lintasan widang 3 . Berdasarkan hasil interpretasi data yang dikorelasikan dengan data bor, menunjukkan bahwa sebagian besar daerah pengukuran memiliki litologi yang didominasi oleh lempung pada pengendapan atas (dasar sungai) dan pada kedalaman 8,5-15 meter didominasi pasir dan lanau.
\end{abstract}

KATA KUNCI： scouring, sedimentasi, GPR, Widang

\section{PENDAHULUAN}

Pembuatan dan pemeliharaan tanggul sungai adalah sangat penting untuk menjaga sungai tetap berfungsi dengan baik. Perkuatan tanggul seperti pembuatan bronjong, plengsengan dan pemasangan tiang pancang merupakan pemeliharaan tanggul agar tidak terjadi kelongsoran.tanggul.

Beberapa jenis perkuatan tersebut telah dilaksanakan pada tanggul sungai Bengawan Solo, namun banyak yang mengalami kegagalan. Kegagalan tersebut karena tanah dasar tanggul sungai adalah tanah lunak yang tidak bisa menahan beban yang berat, sehingga perkuatan-perkuatan yang telah dilaksanakan tidak dapat berfungsi dengan baik [1]. Rusaknya tanggul Bengawan Solo juga terjadi di Desa Widang, Kabupaten Tuban. Di daerah ini tanggul yang telah dibuat mengalami penurunan tanah (longsor) dan di beberapa lokasi, penguatan tanggul berupa bronjong batu yang telah dibuat oleh Dinas terkait juga telah mengalami penurunan tanah pula (lihat Gambar 1).

Untuk itu perlu dilakukan penelitian terhadap kondisi struktur bawah permukaan di Sungai Bengawan Solo, terutama mengenai proses dan bentuk dari sedimentasi sungai. Karena sedimentasi sungai sangat besar pengaruhnya pada penggerusan lapisan tanah baik pada tepi maupun dasar sungai yang

\footnotetext{
*E-MAIL: dwa_desa@physics.its.ac.id
}

nantinya akan mempengaruhi pola dan arah aliran air sungai. Dalam hal ini metode geofisika, khususnya Ground Penentrating Radar (GPR) memainkan peranannya dalam melakukan penelitian tentang kondisi bawah permukaan tersebut.

Metoda GPR adalah metode geofisika dimana pulsa elektromagnetik (EM) dipancarkan ke dalam bumi dan direkam oleh antena di permukaan. Pulsa radar diteruskan, dipantulkan dan dihamburkan oleh strukur permukaan dan anomali di bawah permukaan. Gelombang EM yang dipantulkan dan dihamburkan diterima oleh antenna penerima di permukaan bumi dalam bentuk karakteristik amplitudo gelombang (radargram). Sinyal-sinyal elektromagnetik ini diradiasikan kedalam tanah untuk mendeteksi beberapa anomali pada sifat dielektrik material geologi. Pola refleksi gelombang elektromagnetik yang didapatkan nantinya akan menggambarkan sistem perlapisan sedimentasi dan scouring sungai Bengawan Solo.

\section{DASAR TEORI}

\section{A. Scouring}

Adanya erosi pada bagian dinding sungai merupakan akibat dari proses alami aliran arus sungai yang terjadi secara perlahan. Tingkat erosi ini bergantung pada musim-musim tertentu. Sehingga mempengaruhi tingkat kedalaman dasar sungai dan kecepatan arus sungai. Jika erosi secara terus 


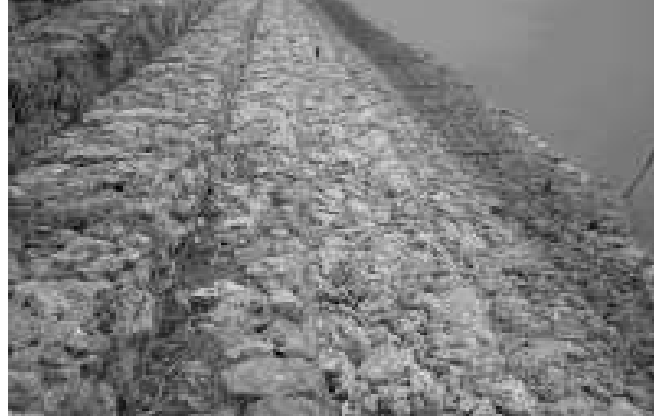

(a)

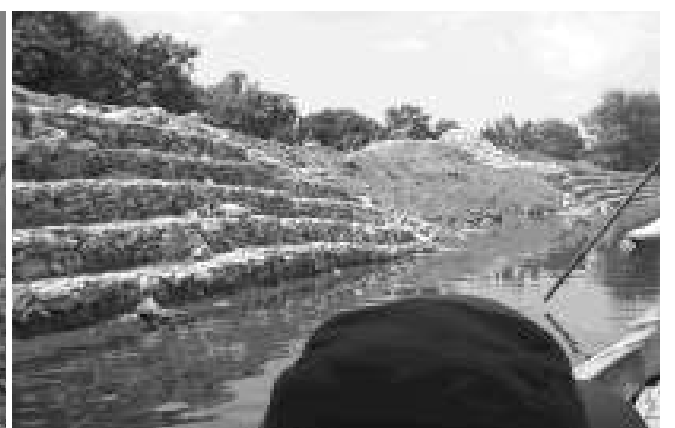

(b)

Gambar 1: (a) Pembangunan tanggul sungai bengawan solo di desa Widang. (b) Kelongsoran tanggul terjadi setelah tanggul berumur kurang dari dua bulan

menerus berlangsung, maka keadaan ini dapat menjadikan dasar sungai menjadi tidak datar (bergelombang), seperti pada Gambar 2. Apabila pada dasar sungai terdapat suatu daerah yang dasarnya lebih dalam dari sekitarnya (membentuk suatu palung), maka daerah ini disebut sebagai scouring [2].

\section{B. Prinsip Dasar GPR}

Ground Penetrating Radar, juga dikenal sebagai ground radar atau georadar, merupakan teknik resolusi tinggi penggambaran lapisan dangkal dan struktur tanah menggunakan prinsip-prinsip perambatan gelombang elektromagnetik yang kedalaman penetrasinya dan besar amplitudo yang terekam bergantung pada sifat kelistrikan dari batuan atau media bawah permukaan dan frekuensi antena yang digunakan. Keuntungan menggunakan gelombang elektromagnetik adalah bahwa sinyal-sinyalnya memiliki panjang gelombang relatif pendek yang dapat dibangkitkan dan diradiasikan kedalam tanah untuk mendeteksi beberapa anomali pada sifat dielektrik material geologi. Penjelasan prinsip dasar GPR secara detail dapat ditemukan di beberapa referensi. [3, 4].

Sifat elektromagnetik yang biasa diukur menggunakan data GPR adalah konstanta dielektrik relatif $\left(\epsilon_{r}\right)$, untuk frekuensi dan survei lapangan yang dipengaruhi oleh air tanah. Travel time (atau kecepatan elektromagnetik) dan amplitudo dari sinyal GPR dapat juga digunakan untuk memperkirakan konstanta relatif dielektrik. Pengukuran travel time ini merupakan pengukuran paling efektif untuk memperkirakan konstanta dielektrik relatif ketika geometri bawah permukaan diketahui atau ketika data variabel offset diperoleh. Pada tabel 1, disajikan contoh rentang harga kecepatan gelombang elektromagnetik yang melalui beberapa material.
TABEL I: Kecepatan gelombang elektromagnetik beberapa jenis batuan [4]

\begin{tabular}{lcccc}
\hline \hline Material & $\epsilon_{r}$ & $\sigma(\mathrm{mS} / \mathrm{m})$ & $\mathrm{v}(\mathrm{m} / \mathrm{ns})$ & $\alpha(\mathrm{dB} / \mathrm{m})$ \\
\hline Udara & 1 & 0 & 0,3 & 0 \\
Air Murni & 80 & 0,01 & 0,033 & $2.10-3$ \\
Air Laut & 80 & $3.10^{3}$ & 0,01 & 103 \\
Pasir Kering & $3-5$ & 0,01 & 0,15 & 0,01 \\
Pasir Basah & $20-30$ & $0,1-1$ & 0,06 & $0,03-0,3$ \\
Limestone & $4-8$ & $0,5-2$ & 0,12 & $0,4-1$ \\
clay & $5-40$ & $2-1000$ & 0,06 & $1-300$ \\
Granit & $4-6$ & $0,01-1$ & 0,13 & $0,01-1$ \\
Rock Salt & 6 & $0,1-1$ & 0,13 & 0,01 \\
Silts & $5-30$ & $1-100$ & 0,07 & $1-100$ \\
Es & $3-4$ & 0,01 & 0,16 & 0,01 \\
Shale & $5-15$ & $1-100$ & 0,09 & $1-100$ \\
\hline \hline
\end{tabular}

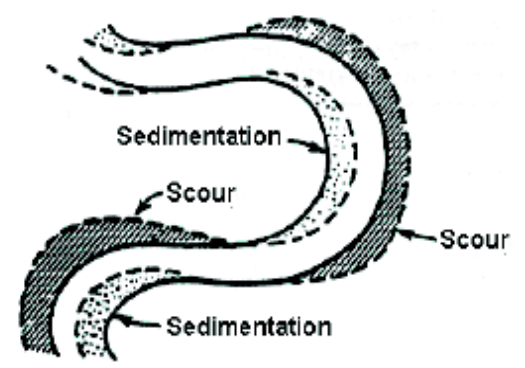

Gambar 2: Peristiwa scouring dan Sedimentasi di badan sungai

\section{METODOLOGI}

\section{A. Lokasi Pengambilan Data}

Lokasi pengambilan data dilakukan di sepanjang Sungai Bengawan Solo di Desa Widang, Kecamatan Sukoharjo, Kabupaten Tuban pada tanggal 20 Agustus 2006. Proses pengambilan data dilakukan di atas perahu dengan melintasi permukaan sungai Bengawan Solo, baik arah tegak lurus maupun sejajar aliran sungai (Lihat Gambar 3 dan Tabel 2).

Pemilihan frekuensi antenna ditentukan oleh tujuan survei 
TABEL II: Orientasi dan Panjang lintasan Pengukuran

\begin{tabular}{lcc}
\hline \hline Nama Lintasan & Orientasi & Panjang (m) \\
\hline Widang 1 & selatan - utara & 151 \\
widang 2 & utara - selatan & 120 \\
widang 3 & utara - selatan & 111 \\
Widang 4 & utara - selatan & 105 \\
Widang 5 & timur - barat & 652 \\
\hline \hline
\end{tabular}

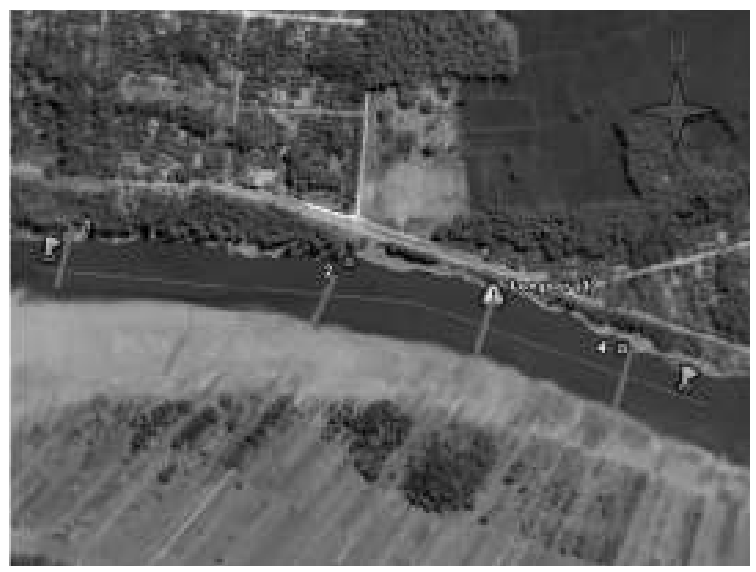

Gambar 3: Posisi lintasan dalam foto satelit

yaitu menentukan kedalaman/resolusi yang dibutuhkan. Pada penelitian sedimentasi Sungai Bengawan Solo di daerah Widang, digunakan frekuensi antena $50 \mathrm{MHz}$. Dengan menggunakan frekuensi tersebut, maka akan didapatkan penetrasi kedalaman hingga 25-30 meter [5].

RAMAC/GPR dapat dilakukan trigging dengan cara yang berbeda pada saat melakukan survey. Proses pengambilan data dilakukan di atas permukaan sungai dengan menggunakan perahu. Karena terdapatnya arus sungai yang labil, maka metode trigging yang digunakan adalah dengan pembacaan interval waktu (time) dengan tetap mempertahankan besarnya kecepatan jalannya perahu konstan.

\section{B. Pengolahan Data}

Hasil pengukuran GPR kemudian diolah dengan mengunakan perangkat lunak REFLEXW Versi 3.5 [6] sehingga profiling/citra gambaran bawah permukaan dapat dicitrakan dengan resolusi tinggi. Alur pengolahan data GPR dapat dilihat pada gambar 4.

\section{INTERPRETASI DATA}

Apabila dilihat dari kondisi geologi dan data bor daerah Bengawan Solo, khususnya Desa Widang tersusun atas endapan fluvial. Fluvial merupakan satuan batuan yang memiliki umur paling muda yaitu kuarter (Holosen) tersusun oleh pasir,

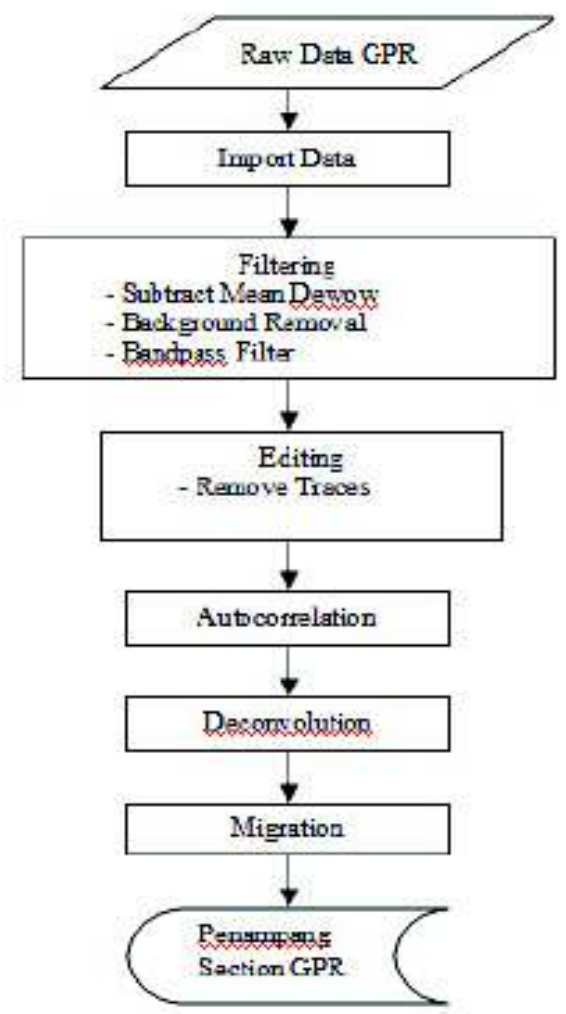

Gambar 4: Diagram alir kerja pengolahan data

lempung, lanau, kerikil hasil dari kegiatan sungai [1]. Endapan fluvial terjadi akibat aktifitas sungai Bengawan Solo, dan saat ini proses pengendapannya masih berlangsung.

Selain itu untuk menentukan karakteristik reflektor dari data GPR yang dihasilkan juga akan dibandingkan dengan tabel penentuan tipe sedimentasi bawah permukaan yang telah dilakukan oleh Bares dan Haeni [7] pada penelitian sebelumnya.

1. Widang 1

Secara garis besar, adanya lapisan sedimentasi dapat terlihat cukup banyak dan tipis-tipis. Lapisan sedimentasi banyak terakumulasi pada bagian dasar sungai (pada kedalaman 3,5 - 6 meter). Dimungkinkan pada daerah ini mengalami pendangkalan sungai yang cukup tebal. Pada area pendangkalan sungai terakumulasi material berupa lempung berpasir. Pasir yang berada di pinggiran sungai, akan tererosi dan terbawa ke dasar sungai akibat arus sungai dan turun naiknya volume air sungai. Kemudian pengendapan pasir ke dasar sungai, diikuti pula dengan terlepasnya ikatan partikel lempung yang merupakan endapan muda yang terdapat pada pinggir sungai yang akhirnya mengendap pula ke dasar sungai (Gambar 5).

2. Widang 2

Sedangkan pada data widang 2, terdapat struktur lapisan tanah yang memiliki amplitudo gelombang 


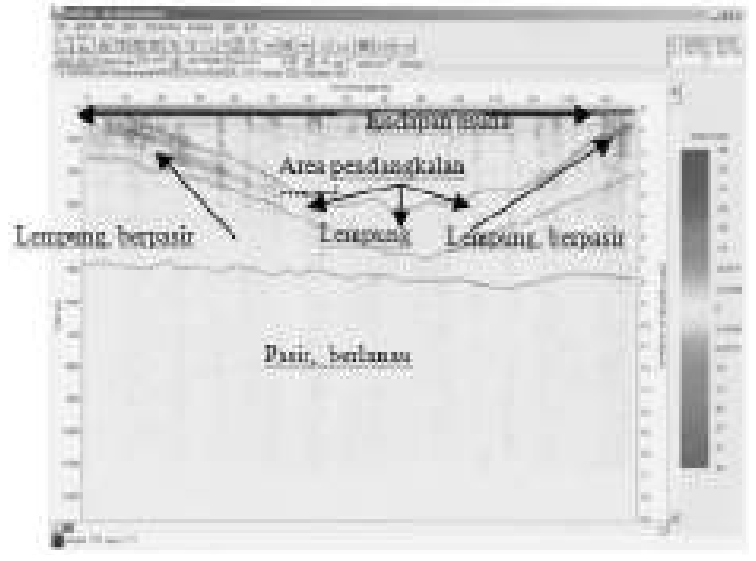

Gambar 5: Interpretasi lintasan widang 1

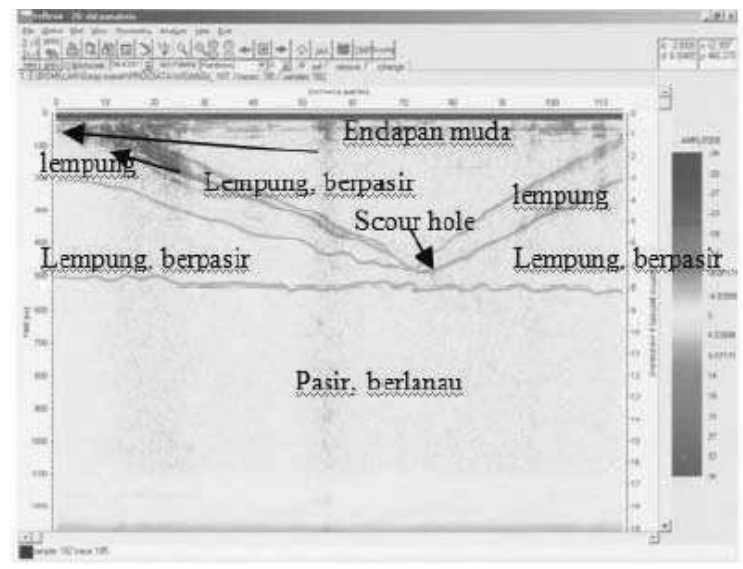

Gambar 6: Interpretasi lintasan widang 2

elektromagnetik yang sangat tinggi (ditunjukkan dengan citra warna ungu), kemudian diselingi dengan lapisan dengan amplitudonya sangat rendah (citra warna biru) yang menumpuk pada kedalaman 0-3 meter di arah timur. Hal ini menunjukkan bahwa lapisan sedimentasi ini memiliki nilai konstanta dielektrik relatif yang cukup tinggi diselingi dengan lapisan sedimentasi dengan nilai konstanta dielektrik relatif yang cukup rendah. Dimungkinkan pada daerah ini sedang terjadi proses erosi yang terus-menerus (Gambar 6).

Selain itu, bentuk dari dasar sungai pada penampang GPR widang dua ini, lebih curam dan dalam dibandingkan data lintasan widang satu. Apalagi pada lintasan ini terdapat lubang scouring (scour hole), yang merupakan lubang akibat longsoran karena erosi di sungai. Dengan adanya scour hole ini menyebabkan potensi penggerusan tanah di sekitar tanggul menjadi semakin tinggi.

3. Widang 3

Untuk data lintasan widang 3, model lapisan sedimentasinya juga hampir sama dengan data lintasan widang

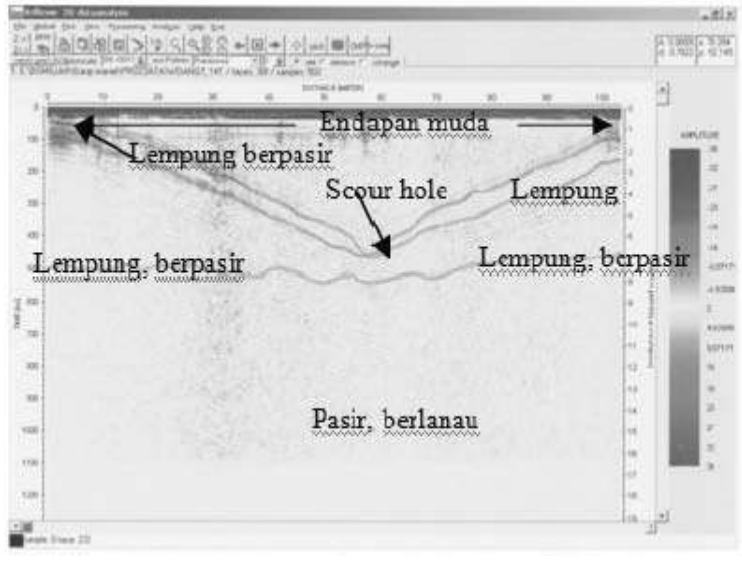

Gambar 7: Interpretasi lintasan widang 3

2. Pada saat pengambilan data lintasan 3 ini, dilakukan pada daerah sungai yang mengalami pembelokan. Hal ini bisa terlihat dari puncak dasar sungai pada lintasan widang 2 yang berada pada jarak 70 meter, sedangkan pada data widang 3 ini puncak dasar sungai terletak pada jarak 60 meter. Sebagai implikasi dengan adanya arah sungai yang berbelok menyebabkan debit air menjadi lebih tinggi pada arah tikungan sungai. Dibagian tikungan, timbul gaya sentripetal yang mengakibatkan aliran terdesak ke tikungan luar lalu membelok ke tebing luar dan bawah sehingga menyebabkan terjadinya penggerusan di tikungan luar dan dasar sungai.

Dalam penampang radargram GPR ini (Gambar 7), juga terdapat scour hole di dasar sungai dan kemiringan dasar sungai juga cukup curam. Sehingga dapat dikatakan bahwa pada lintasan widang 3 ini juga memiliki potensi longsor yang cukup tinggi.

4. Widang 4

Pada data lintasan widang 4, model lapisan sedimentasinya juga hampir sama dengan data widang 2 dan widang 3 . Model dinding sungai juga menggambarkan daerah yang cukup curam, yang juga dapat mengakibatkan terganggunya ketidakstabilan dari tanggul. Namun pada lintasan ini tidak ada scour hole, sehingga dapat dikatakan potensi longsor lebih kecil. Tetapi potensi terbentuknya scouring pada daerah ini dapat saja terjadi. Mengingat keadaan kemiringan dasar sungai dan endapan muda yang terdiri atas lempung mulai tergerus ke dasar sungai. Berikut, Gambar 8 merupakan gambar penampang dari widang 4 .

\section{Widang 5}

Untuk data lintasan widang 5, pengukuran dilakukan dengan arah lintasan sejajar aliran sungai yaitu dari hilir ke hulu (selatan - utara). Pengambilan data dilakukan agak ke pinggir sungai, yang bertujuan untuk melihat sedimentasi pada pinggiran sungai. Dari penampang GPR bahwa dasar sungai berada pada kedalaman 1-2 meter. Dalam penampang ini (Gambar 9) tampak 


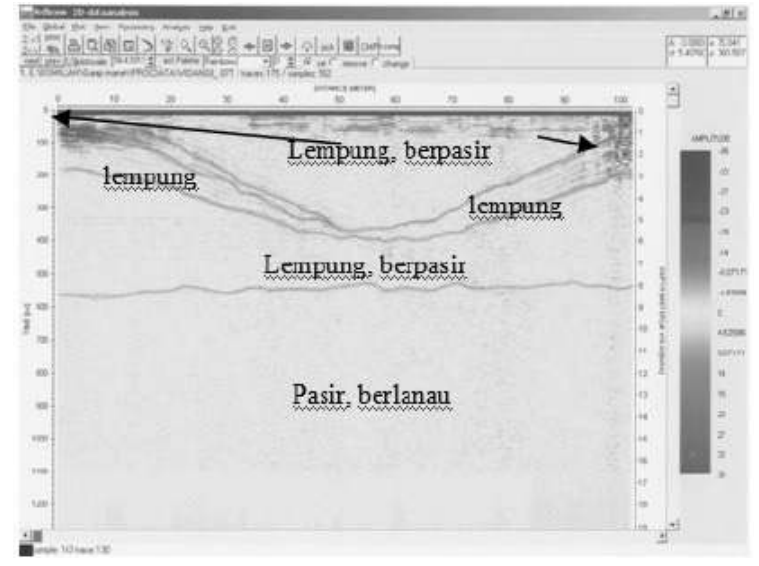

Gambar 8: Interpretasi lintasan widang 4

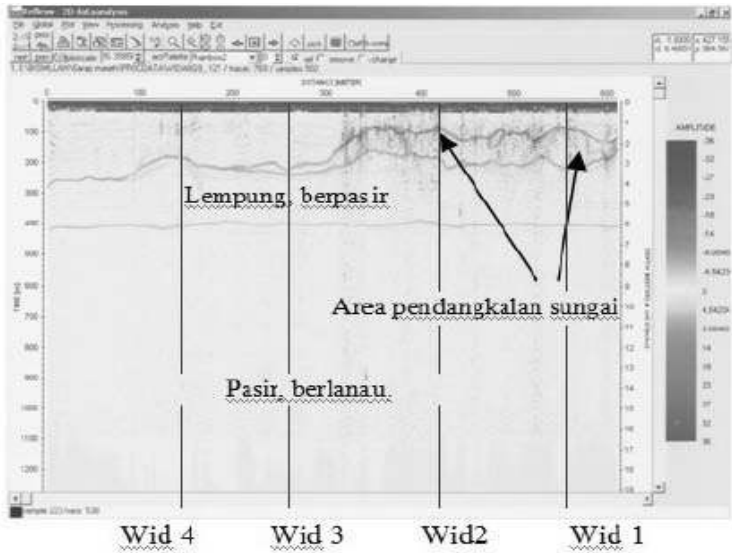

Gambar 9: Interpretasi lintasan widang 5

bahwa dasar sungai tidak rata (bergelombang). Selain itu dapat ditemui lapisan sedimentasi yang cukup tebal berada pada daerah hulu sungai (daerah sekitar lintasan widang 1). Seperti yang dikatakan sebelumnya bahwa pada daerah widang 1 terdapat pendangkalan sungai. Hal ini terbukti dengan adanya lapisan sedimentasi yang nampak jelas dan menebal pada daerah menuju hulu (jarak 320 - 600 meter).

Setelah menganalisa kelima data ini, dapat diamati bahwa terdapatnya pendangkalan dasar sungai pada daerah lintasan widang 1 (ke arah utara / hulu sungai). Kemudian secara berangsur-angsur terdapat penurunan dasar sungai ke arah hilir sungai. Adanya penurunan ini mengakibatkan cekungan sungai bertambah curam, sehingga potensi terjadinya runtuhnya tanggul (longsor) sangat besar. Ditambah lagi dengan adanya arah belokan sungai, yang menyebabkan erosi pada tanggul semakin kuat. Apabila dilihat kondisi tanggul di daerah ini, di beberapa tempat memang telah mengalami kerusakan seperti yang terlihat pada gambar 1 .

Sedangkan dari hasil korelasi radargram GPR dengan data bor dari semua data, secara keseluruhan menunjukkan adanya korelasi pula dengan amplitudo gelombang elektromagnet. Pada perlapisan sedimentasi sungai menunjukkan selang-seling nilai amplitudo yang tinggi dan lemah. Hal ini dimungkin oleh karena jenis tanah terdapat kandungan pasir. Dimana pasir memiliki porositas yang cukup besar, sehingga pori batuannya mudah terisi oleh fluida. Kemudian.adanya fluida yang memasuki pori batuan mengakibatkan nilai konstanta dielektirknya menjadi semakin besar, karena kecepatan penjalaran gelombang semakin kecil dan hal ini dapat ditunjukkan dengan adanya amplitudo yang lemah. Kemudian lapisan pasir ini bertumpuk dengan jenis batuan lainnya yaitu lempung sehingga niai amplitudonya bervariasi, yang menadakan bahwa pada daerah ini terjadi proses erosi yang terus menerus [7].

Dari hasil kelima data tersebut, akumulasi lapisan tanah lempung dan pasir, banyak terakumulasi pada sisi kiri penampang yang merupakan bagian timur tanggul sungai. Maka pada daerah tanggul sebelah timur, menjadi mudah tererosi dan longsor. Hal ini terbukti pada penampakan visual di lapangan, tanggul yang mengalami kerusakan paling parah terdapat pada daerah tanggul sebelah timur (lihat Gambar 3).

\section{SIMPULAN}

Berdasarkan hasil kajian di atas maka dalam dapat disimpulkan beberapa hal sebagai berikut:

1. Terdapat pedangkalan sungai pada data lintasan widang 1, yaitu berada pada jarak 60 - 100 meter dati titik 0 (titik awal).

2. Pada lintasan widang 2 dan 3, mempunyai potensi kelongsoran yang tinggi, dikarenakan memiliki dasar sungai yang cukup curam dan terdapat scour hole.

3. Secara keseluruhan dari 5 data yang telah diinterpretasikan memiliki sistem perlapisan sedimentasi yang hampir sama. Yaitu pada bagian ke arah dekat permukaan (tanggul) didominasi oleh material lempung yang bersisipan dengan pasir yang pori batuannya telah tersisipi oleh fluida. Sehingga penggerusan tanggul oleh fluida (air sungai) dapat terus terjadi.

4. Adanya fluida yang masuk ke pori batuan diindikasikan dengan adanya amplitudo gelombang elektromagnet yang lemah. 
[1] Warnana, D.D dan Ian R., Penerapan Metode Geolistrik dalam analisa keandalan tanggul sungai: studi kasus Sungai Bengawan Solo, Proc Seminar Fisika dan Aplikasinya, Surabaya, 2007.

[2] Xanthakos, P., Bridge Substructure and Fondation Design (Prentice Hall, 1995).

[3] Reynolds, John M., An Introduction to Applied and Environmental Geophysics (John Wiley \& Sons, New York, 1997).
[4] Annan, A.P., Ground Penetrating Radar Workshop Notes (Sensors \& Software Inc, Canada, 1992).

[5] MalaGeoscience, Ramac?GPR Software Manual (Swedia, 1997).

[6] Sandmeier, K.J., ReflexW (Software version 3.5.7, 2005).

[7] Bares, M and Haeni, F.P., Ground Water, 29(3), 375-386 (1991). 